\title{
Customers Online Shopping Experience - Comparison Among Amazon, Flipkart \& Snapdeal
}

\author{
Devaki Shetty, Saraswathi Moorthy
}

\begin{abstract}
Today customers have a variety of online shopping sites from where they can make their purchases. Online shopping helps the customers to purchase all sorts of goods and services from all around the world. Online shopping is a method of shopping, in which the customers can purchase goods and services from any part of the world through the internet. Online shopping experienceof the customers with some online sites may bepositive whereas with some other sites it may be negative. Experience is gathered after making a shopping decision. A positive experience results due to better quality of products and services, reasonable pricing, timely delivery of products, offers and discounts (including festive offers and discounts), end of season sale etc. Positive experience leads to repetitive purchases. Negative experience results due to defective products, delay in the delivery of products, poor after sales services, delay or no refund given, no exchange facility etc. With reference to the three giant companies namely Amazon, Flipkart and Snapdeal, for the purpose of this study, primary data was collected through a structured Questionnaire and administered to 60 respondents. A simple percentage method was used to analyse the data and a non-parametrical test, Chi-square method was used to test the hypothesis. The study concludes that shopping experience by Amazon is better than the other two companies.
\end{abstract}

Keywords: Online shopping, Customers, Shopping Experience.

\section{INTRODUCTION}

Online shopping is one of the emerging trends in the current market.This research paper attempts to study, compare and evaluate the online shopping experience of customers with reference to three giant companies Amazon, Flipkart and Snapdeal. Online shopping refers to shopping of goods and services through the usage of web browser. This method of shopping is becoming popular due to the development in the technology, laziness or lack of time among the customers to personally visit the physical stores, 24/7 shopping provided by online players, Convenience in buying, Variety of choices available, the availability of cheap internet among the masses, etc.

There are many online companies that provide online shopping facility namely,Amazon, Flipkart, Snapdeal, Myntra,Jabong, Nykaa, Tata cliq etc.This paper is focusing

Revised Manuscript Received on December 05, 2019.

* Correspondence Author

Ms. Devaki Shetty*, Ph.D. Research Scholar, R.J. College (Autonomous) Maharashtra, India.

Dr. Saraswathi Moorthy, Associate Professor and Head - Accountancy, R.J College (Autonomous), Maharashtra, India. on the select three companies that are considered to be the leaders in the market, namely; Amazon, Flipkart and Snapdeal.

\section{CURRENT MARKET SCENARIO IN INDIA.}

The customers today have a variety of options to make their purchases from physical as well as online platform. The physical shopping is the oldest method of shopping which is slowlybeingsubstituted by the latter option of online shopping. This change in the choice of customers is due to the variety in the choices offered, huge rate of discounts, prompt delivery,24/7 shopping, quick redressal of grievances etc.

\section{ObJective OF THE STUdY}

- To study the customers online shopping experience of the three online players.

- To compare the customers online shopping experience of the three online players.

- To evaluate the customers online shopping experience of the three online players

Hypothesis of the study

Ho: There is no significant difference in the shopping experience of customers of the three online players.

H1: There is a significant difference in the shopping experience of customers of the three online players.

\section{REVIEW OF LITERATURE}

Choudhury, Deepjyoti and Dey, Abhijit (2014) in their paper attempts to identify the factors such as internet literacy, gender, educational qualification, website usability and online product price impact on online shopping. The study was conducted among the students of Assam university. Sample size consisted of 200 respondents and the result of the study showed that there is a significant relationship of online shopping between internet literacy, gender and online product price. The study further revealed that there is no relationship of online shopping with education and website usability.

Kothari, Pritam and Maindargi, Shivganga (2016) in their paper focuses on the factors which affect consumer perception about online shopping. It was found through the

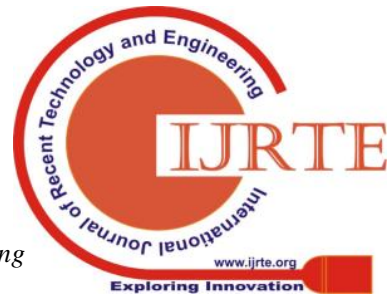


study that cognition, sensed usefulness, comfort of use, sensed enjoyment and security are the five factors that affect consumer perception about online shopping.

The study was conducted by choosing 100 respondents from the city of Solapur. The well-structured questionnaire was prepared to collect the opinion of the respondents. The study concludes that due to revolution of telecommunication sector number of customers using online shopping has increased but still most of the customers first choice is manual shopping.

Trevinal, Aurelia and stenger, Thomas (2012) in their paper focuses on the shopping experience in the online environment from three aspects such as the physical, ideological, and pragmatic dimensions. An exploratory research study using qualitative research method with four focus groups consisting of 31 consumers belonging to different age group, gender and experience was conducted inFrance. The study reveals that it is relevant to use the theoretical framework of consumption in the online context, the dimensions of online shopping experience enables to analyse the global online shopping experience lived by consumers and their companions.

\section{Limitations of the Study}

The sample collected for the study is restricted to the geographical area of Mumbai city.

Only three Online players Amazon, Flipkart and Snapdeal have been covered for the purpose of the study.

\section{Scope of the Study}

The scope of the study includes both male and female customers who are familiar with online shopping. The geographical scope includes the central location (Dadar Mulund), Harbour location (Kurla - Mankhurd) and western location (Dadar - Borivali) of Mumbai City.

\section{RESEARCH METHODOLOGY}

Sources of Data: Both primary as well as secondary sources of data have been used in this research paper. For the primary sources, Questionnaire has been administered to 60 respondents and the data collected has been suitably analysed to test the hypothesis. The secondary sources of data include published research papers, e-books, online journals etc.

Sample: The sample has been collected from the geographical region of the city of Mumbai. Convenient sampling method is used to collect the information related to study. Accordingly, 60 respondents have been included in the study.

\section{Customers Online shopping Experience}

Today customers have a variety of online shopping sites from where they can make their purchases. Online shopping helps the customers to purchase all sorts of goods and services from all around the world. Online shopping is a method of shopping, in which the customers can purchase goods and services from any part of the world through the internet.

Online shopping experienceof the customers with some online sites may bepositive whereas with some other sites it may be negative. Experience is gathered after making a shopping decision. A positive experience results due to better quality of products and services, reasonable pricing, timely delivery of products, offers and discounts (including festive offers and discounts), end of season sale etc. Positive experience leads to repetitive purchases.

Negative experience results due to defective products, delay in the delivery of products, poor after sales services, delay or no refund given, No exchange facility etc. If the experiences of the customer are negative, he/she will stop buying any products from the following online site and may also pass this message to others (including his friends, relatives etc) through the powerful social media. This may affect the company's image and turnover all over the world.

In this research paper, the online shopping experience of the customers is studied with reference to the three giant companies namely Amazon, Flipkart and Snapdeal. The reason being Amazon and Flipkart are having around 30\% market share in the India. Snapdeal is the third largest online company having around $10 \%$ market share in the country after Amazon and Flipkart.

\section{Research Findings}

Analysis of Data: To study the online shopping experiences of customers data was collected from 60 respondents and the analysis of the same is discussed below:

Table - I: Gender and Age of Respondents

\begin{tabular}{|c|c|c|c|c|c|c|}
\hline & Male & $\%$ & Female & $\%$ & Total & $\%$ \\
\hline $\begin{array}{c}\text { Under } 21 \\
\text { years }\end{array}$ & 02 & 3.33 & 03 & 5 & 05 & 8.33 \\
\hline $21-30$ years & 12 & 20 & 27 & 45 & 39 & 65 \\
\hline 31 - 40 years & 07 & 11.67 & 06 & 10 & 13 & 21.67 \\
\hline $\begin{array}{c}41-49 \\
\text { years }\end{array}$ & Nil & NIL & 02 & 3.33 & 02 & 3.33 \\
\hline$<50$ years & 01 & 1.67 & $\mathrm{NIL}$ & $\mathrm{NIL}$ & 01 & 1.67 \\
\hline TOTAL & 22 & 36.67 & 38 & 63.33 & 60 & 100 \\
\hline
\end{tabular}




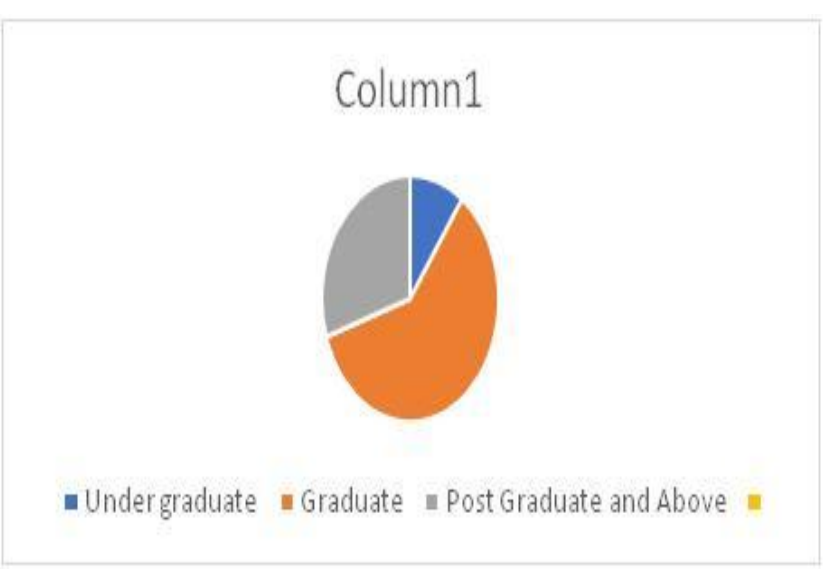

The figure 1 shows that majority of respondents were educated and least number of respondents were under graduates, the maximum no of respondents were graduates $(60 \%)$ followed by post graduates $(30 \%)$.

From the above, table 1 and figure 1 showing the age, gender and educational level of respondents, the online companies can formulate marketing strategies depending upon the age, gender and education level in order to focus on their target audience effectively.

Almost 97 percent of the respondents included in the survey had purchased goods and services through online and all ofthemwere alsofamiliar with Amazon, Flipkart and Snapdeal. This is the good sign for the online companies, that the audience today are familiar and aware about online methods of shopping. The customers nowadays are indulging this method of shopping due to various benefits associated with it, such as it offers lot of comfort to the customers, and leaves them with lot of leisure time.

The frequency of shopping through online- 33.33 percent of the respondents purchased goods monthly basis, $33.33 \%$ of the respondents onhalf yearly basis, $(13.33 \%)$ on a weekly basis, fortnightly basis (10\%)and yearly basis (10\%) respectively. This data indicates that there is lot of scope for the online companies to frame effective marketing strategies to encourage the customer to indulge in online shopping regularly.

The preferred online site on basis of reasonable pricing is Amazon (66.67\%), followed by Flipkart (23.33\%) and Snapdeal $(10 \%)$. The above data indicates that Flipkart and Snapdeal have to work more on providing reasonable pricing to customers.

On the basis of quality products and services, prompt and timely delivery, variety on the basis of choices to customers, quick refund and replacement of products, user friendly website, adequate customer reviews provided and live chat option to resolve queries, Amazon is the preferred site with more than $65 \%$ approximately and Flipkart is the second preferred site with about $25 \%$ and Snapdeal with $10 \%$. This data indicates that Flipkart and Snapdeal have to focus more on the above aspects to compete with Amazon. They have to devise effective strategies to improve on the above services provided by them.

On the basis of referring the online sites to friends and relatives following is the Analysis

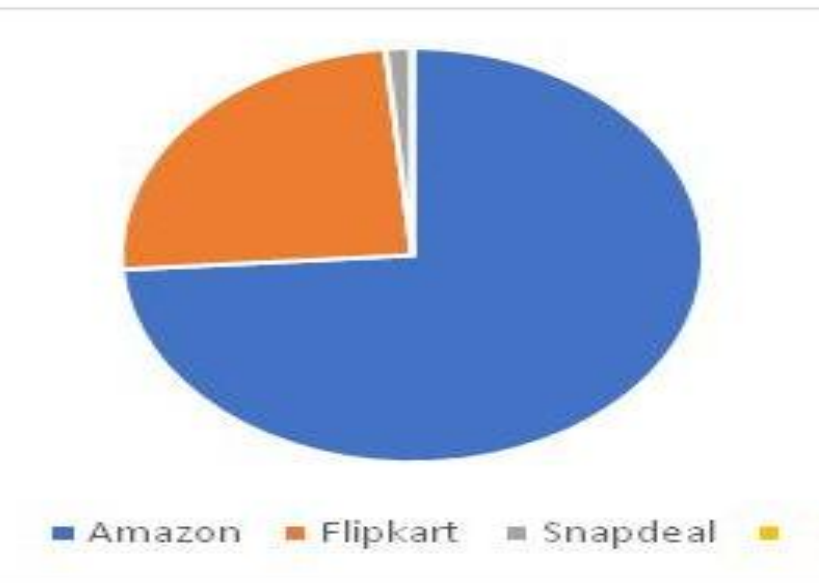

The diagram shows that maximum customers recommend Amazon to their friends and relatives. This proves that Amazon is popular, well-known and hence the leader in the current market scenario.

On the basis of overall analysis, most of the customers have preferred Amazon (66.67\%)on the basis of better shopping experience provided. Second preferred site was Flipkart (23.33\%) and on third place was Snapdeal (10\%). This indicates that Flipkart and Snapdeal has lot of scope to improve their services in order to compete with Amazon and to increase their market share.

\section{Observation}

\section{The above analysis of data shows that}

i) The audience today are familiar about online methods of shopping. The customers nowadays are accepting this method of shopping due to various benefits associated with it, such as it offers lot of comfort to the customers, and leaves them with lot of leisure time.

ii) There is lot of scope for the online companies to frame effective marketing strategies to encourage the customer to indulge in online shopping regularly.

iii) Flipkart and Snapdeal have to work more on providing reasonable pricing to customers.

iv) Flipkart and Snapdeal have to focus more on the aspects such as variety in the choices offered, huge rate of discounts, prompt delivery, 24/7 shopping, quick redressal of grievances to compete with Amazon. They have to devise effective strategies to improve on the services provided by them.

v) Flipkart and Snapdeal has lot of scope to improve their services in order to compete with Amazon and also to increase their market share.

\section{Testing of Hypothesis}

Hypothesis was tested on the basis of Chi Square method (Non-parametric test) at 5\% level of Significance.

Published By: 
Better Customer Experience provided by online players

Amazon

Flipkart

Snapdeal

No of Responses

40

16

4

Ho: There is no significant difference at the shopping experience of customers of the three online players.

H1: There is a significant difference at the shopping experience of customers of the three online players.

Expected Response $=40+16+4 / 3=60 / 3=20$

Table - II: Chi-Square - Shopping Experience of Customers

\begin{tabular}{|c|c|c|c|}
\hline $\begin{array}{r}\text { Observed } \\
\text { Responses(O) }\end{array}$ & $\begin{array}{r}\text { Expected } \\
\text { Responses (E) }\end{array}$ & (O-E)2 & $(\mathrm{O}-\mathrm{E}) 2 / \mathrm{E}$ \\
\hline 40 & 20 & 400 & 20 \\
16 & 20 & 16 & 0.8 \\
4 & 20 & 256 & 12.8 \\
\hline & & & 33.6 \\
\hline
\end{tabular}

$\chi^{2} \mathrm{cal}=\sum[(0 . \mathrm{E}) 2 / \mathrm{E}]$

$$
=33.6
$$

Degree of Freedom $(\mathrm{x})=(\mathrm{n}-1)=(3-1)=2$

For $\mathrm{x}=2,(\times 20.05)=5.99($ table value $)$

The calculated value of $x 2$ is greater than the table value (x20.05)

Therefore, H0 is rejected and H1 is accepted.

There is a significant difference in the shopping experience of customers of the three online players.

\section{Conclusion}

"We treat our customers as invited guests to party, we are the hosts. It's our job every day to make every important aspect of the customer experience a little bit better." A quote by Jeff Bezos, CEO of Amazon.

The above quote justifies how important it is for the company to improve customer experience. The study suggests that there is significant difference in the shopping experience of the three online players Amazon, Flipkart and Snapdeal. The study shows the shopping experience provided by Amazon is greater than the other two online players. This is due to quality product and services, timely and prompt delivery, reasonable pricing and variety on the basis of choices to customers, quick refund and replacement of products, user friendly website, adequate customer reviews provided and live chat option to resolve queries.

\section{REFERENCES}

1. Choudhury, Deepjyoti and Dey, Abhijit (2014) in their paper "Online Shopping attitude among the youth: A study on University Students" in International journal of entrepreneurship and development studies, January, 2014.

2. Kothari, Pritam and Maindargi, Shivganga (2016) in their paper "A Study of Customer Attitude towards online shopping in India and its Impact: With special Reference to Solapur City" in International Research of Advanced Research, Ideas and innovations in Technology, (ISSN: 2454-132X), Vol2, issue 6.

3. Trevinal, Aurelia and stenger, Thomas (2012) in their paper "Online shopping experiences: a qualitative research" in Academy of Market Science Annual Conference, New Orleans, May 2012.

4. Gilbert, Sara (2013), The story of Amazon.com, Kaveri Print Process Pvt.Ltd, ISBN 978-81-8495-437-1

5. ww.forbes.com/sites/johnkoetsier/2018/05/18/report-amazon-india-worth16b-with-30-market-share-will-hit-70b-gmv-in-2027/\#1bbb4a726b95
6. https://qz.com/india/984416/everything-that-has-gone-down-at-snapdeal-s ince-the-flipkart-merger-rumours-began/

\section{AUTHORS PROFILE}

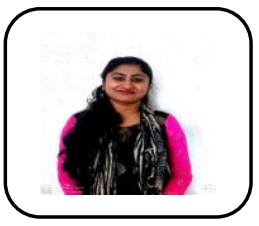

2016.

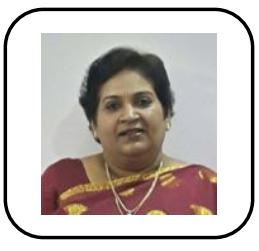
in the city of Mumbai". Post-doctoral collaboration with Homi Bhabha Centre for Science Education (TIFR), Mumbai-(November 2015) - Was invited as a short term visitor to finalize the project titled- "Health and Fitness Awareness of College students in Suburban Mumbai- (Case study of R.J.College, Mumbai)". experience: UG: 6 years: PG: 5 years teaching Accountancy. Publications: 2, Research Pursuing Ph.D. from University of Mumbai Title: Study of warehouses in Bhiwandi from online traders (Flipkart, Amazon \& Snap deal)Research Centre: R.J College, Ghatkopar, Mumbai. Registered: November

Dr. Saraswathi Moorthy, M.Com, Ph.D., NET and SLET. Teaching experience UG 24 Years teaching accountancy. Publications -24 papers and edited two books. Doctoral study (October 2008) Titled "Emerging Trends in Direct Selling -A Critical Study of Impact of Distribution and Networking on Consumers". Mumbai University sponsored Minor Research Project No 212 (2010-11) titled "A study of

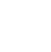

